
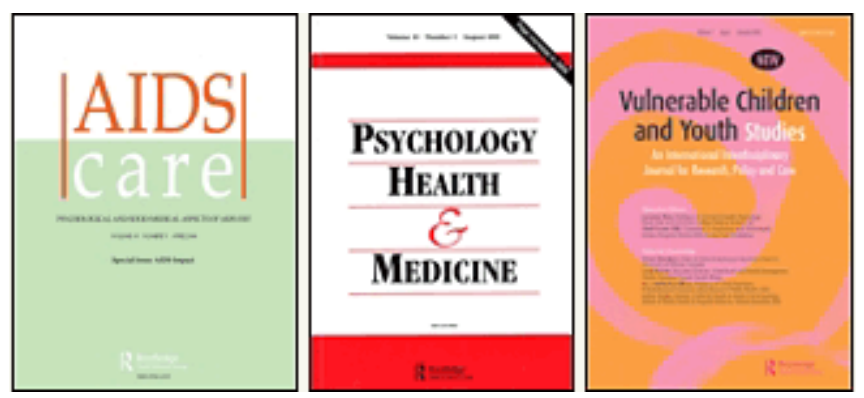

\title{
Sexual dysfunction in HIV positive men is multi-factorial: a study of prevalence and associated factors.
}

\begin{tabular}{|r|l|}
\hline Journal: & $\begin{array}{l}\text { AIDS Care - Psychology, Health \& Medicine - Vulnerable Children } \\
\text { and Youth Studies }\end{array}$ \\
\hline Manuscript ID: & AC-2006-08-0134.R1 \\
\hline Journal Selection: & AIDS Care \\
\hline Keywords: & sexual dysfunction, impotence, antiretroviral therapy, highly active. \\
\hline \multicolumn{2}{|c}{} \\
\hline
\end{tabular}

\section{今 scholarONE" \\ Manuscript Central}


Table 1

Univariate logistic regression model showing likelihood of:

1) Moderate, severe self reported erectile dysfunction (EDF)

2) Moderate, severe impairment of sexual desire (LSD)

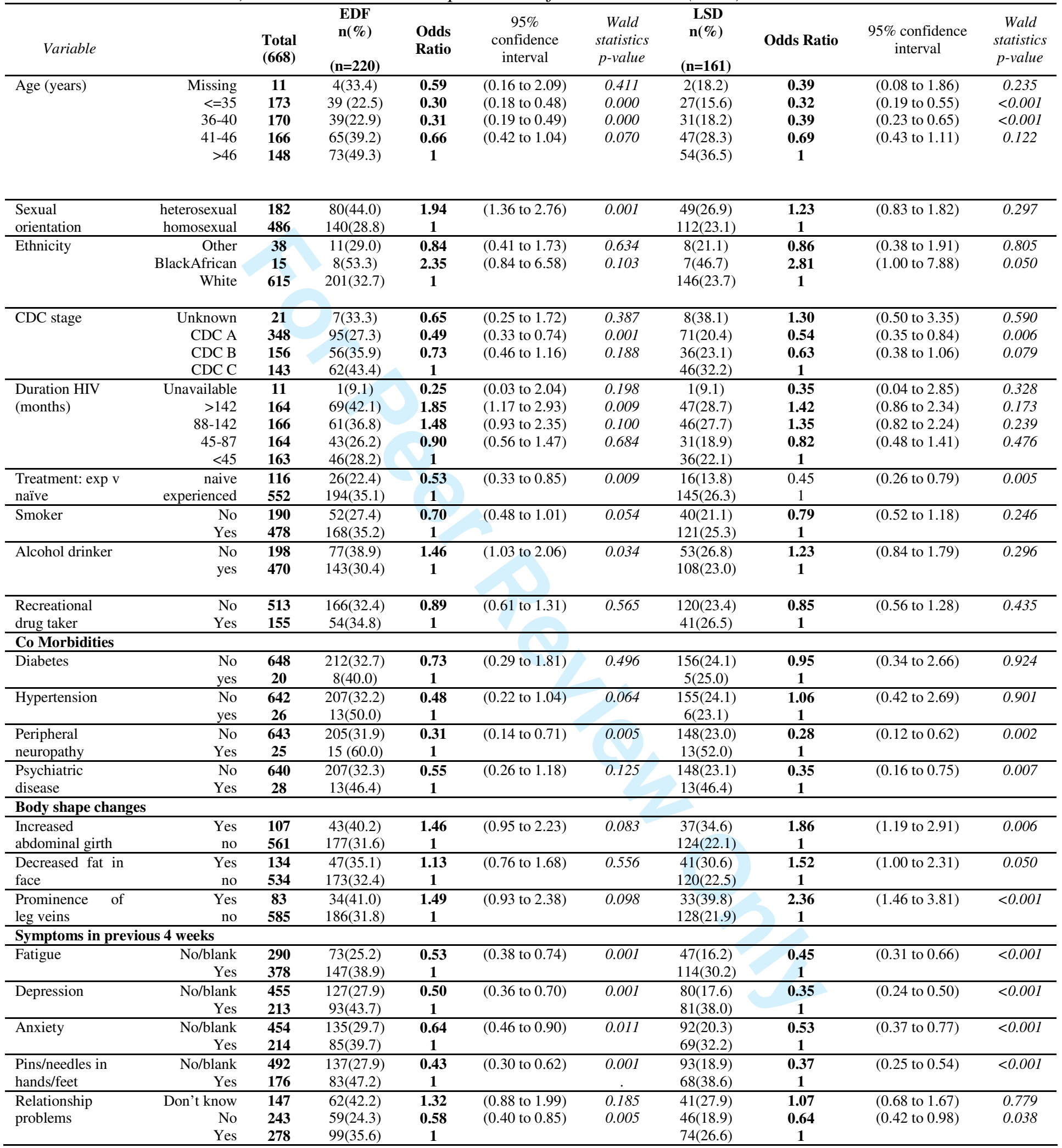




\begin{tabular}{|c|c|c|c|c|c|c|c|c|c|c|}
\hline Variable & & $\begin{array}{l}\text { Total } \\
(668)\end{array}$ & $\begin{array}{c}\text { EDF } \\
\mathbf{n}(\%) \\
(\mathbf{n}=\mathbf{2 2 0}) \\
\end{array}$ & $\begin{array}{l}\text { Odds } \\
\text { Ratio }\end{array}$ & $\begin{array}{c}95 \% \\
\text { confidence } \\
\text { interval }\end{array}$ & $\begin{array}{c}\text { Wald } \\
\text { statistics } \\
\text { p-value }\end{array}$ & $\begin{array}{c}\text { LSD } \\
\mathbf{n}(\%) \\
(\mathrm{n}=161) \\
\end{array}$ & Odds Ratio & $\begin{array}{c}95 \% \text { confidence } \\
\text { interval }\end{array}$ & $\begin{array}{c}\text { Wald } \\
\text { statistics } \\
\text { p-value }\end{array}$ \\
\hline \multicolumn{11}{|l|}{ Laboratory values } \\
\hline \multirow[t]{5}{*}{ CD4 count } & Unavail & 4 & $0(0.00)$ & - & - & - & $1(25.0)$ & 1.51 & (0.15 to 15.03$)$ & 0.725 \\
\hline & $<333$ & 166 & $64(38.6)$ & 1.91 & (1.19 to 3.06$)$ & 0.007 & $47(28.3)$ & 1.79 & (1.06 to 3.01$)$ & 0.028 \\
\hline & $333-498$ & 166 & $64(38.6)$ & 1.91 & (1.19 to 3.06$)$ & 0.007 & $40(24.1)$ & 1.44 & (0.85 to 2.45$)$ & 0.180 \\
\hline & $499-709$ & 166 & $51(30.7)$ & 1.35 & (0.83 to 2.19$)$ & 0.221 & $43(25.9)$ & 1.58 & (0.94 to 2.68$)$ & 0.086 \\
\hline & $>=710$ & 166 & $41(24.7)$ & 1 & & & $30(18.1)$ & 1 & & \\
\hline \multirow[t]{5}{*}{ Viral load } & Unavai & 6 & $1(16.7)$ & 0.41 & (0.05 to 3.50$)$ & 0.411 & $3(50.0)$ & 3.13 & (0.62 to 15.72$)$ & 0.166 \\
\hline & $>10^{5}$ & 38 & $12(31.6)$ & 0.93 & (0.46 to 1.90$)$ & 0.852 & $9(23.7)$ & 0.97 & $(0.45$ to 2.11$)$ & 0.942 \\
\hline & $10^{4}-10^{5}$ & 79 & $24(30.4)$ & 0.88 & (0.53 to 1.48$)$ & 0.639 & $16(20.3)$ & 0.80 & (0.44 to 1.43$)$ & 0.444 \\
\hline & $10^{3}-10^{4}$ & 70 & $26(37.1)$ & 1.20 & (0.71 to 2.02$)$ & 0.499 & $18(25.7)$ & 1.08 & (0.61 to 1.93$)$ & 0.785 \\
\hline & $<10^{3}$ & 475 & $157(33.1)$ & 1 & & & $115(24.2)$ & 1 & & \\
\hline \multirow[t]{5}{*}{ Blood glucose } & Unavail & 43 & $13(30.2)$ & 0.88 & (0.42 to 1.82$)$ & 0.721 & $14(32.6)$ & 1.92 & $(0.91$ to 4.05$)$ & 0.089 \\
\hline & $<4.8$ & 162 & $50(30.9)$ & 0.90 & (0.56 to 1.45$)$ & 0.668 & $41(25.3)$ & 1.34 & (0.79 to 2.28$)$ & 0.273 \\
\hline & $4.8-5.0$ & 41 & $16(39.0)$ & 1.29 & (0.63 to 2.63$)$ & 0.480 & $12(29.3)$ & 1.64 & (0.75 to 3.58$)$ & 0.213 \\
\hline & $5.1-5.9$ & 268 & $90(33.6)$ & 1.02 & (0.67 to 1.56$)$ & 0.922 & $63(23.5)$ & 1.22 & (0.75 to 1.98$)$ & 0.423 \\
\hline & $>=5.9$ & 154 & $51(33.1)$ & 1 & & & $31(20.1)$ & 1 & & \\
\hline \multirow[t]{5}{*}{ Total cholesterol } & Unavail & 13 & $3(23.1)$ & 0.60 & (0.16 to 2.27$)$ & 0.456 & $5(38.5)$ & 1.90 & (0.59 to 6.07$)$ & 0.279 \\
\hline & $<4.3$ & 156 & $55(35.3)$ & 1.10 & (0.71 to 1.70$)$ & 0.679 & $29(18.6)$ & 0.69 & (0.41 to 1.16$)$ & 0.164 \\
\hline & 4.3-4.9 & 105 & $36(34.3)$ & 1.05 & (0.64 to 1.73 ) & 0.844 & $27(25.7)$ & 1.05 & (0.61 to 1.81$)$ & 0.854 \\
\hline & $5.0-5.9$ & 192 & $59(30.7)$ & 0.89 & (0.58 to 1.37$)$ & 0.604 & $50(26.0)$ & 1.07 & (0.68 to 1.69$)$ & 0.769 \\
\hline & $>=6$ & 202 & $67(33.2)$ & 1 & & & $50(24.8)$ & 1 & & \\
\hline \multirow[t]{3}{*}{ HDL cholesterol } & Unavail & 171 & $50(29.2)$ & 0.59 & $(0.38$ to 0.90$)$ & 0.013 & $42(24.6)$ & 0.98 & (0.62 to 1.56$)$ & 0.940 \\
\hline & $0-1.3$ & 272 & $77(28.3)$ & 0.56 & (0.39 to 0.81$)$ & 0.002 & $63(23.2)$ & 0.91 & (0.60 to 1.38$)$ & 0.653 \\
\hline & $>=1.4$ & 225 & $93(41.3)$ & 1 & & & $56(24.9)$ & 1 & & \\
\hline \multirow[t]{5}{*}{ Trigylcerides } & Unavail & 31 & $9(29.0)$ & 0.77 & (0.33 to 1.78$)$ & 0.540 & $8(25.8)$ & 1.03 & (0.43 to 2.47$)$ & 0.952 \\
\hline & $<1.1$ & 166 & $45(27.1)$ & 0.70 & (0.44 to 1.11$)$ & 0.133 & $33(19.9)$ & 0.73 & (0.44 to 1.23$)$ & 0.236 \\
\hline & $1.1-1.9$ & 132 & $51(38.6)$ & 1.18 & (0.74 to 1.90$)$ & 0.482 & $37(28.0)$ & 1.15 & (0.69 to 1.92$)$ & 0.593 \\
\hline & $2.0-2.9$ & 169 & $56(33.1)$ & 0.93 & (0.59 to 1.46$)$ & 0.482 & $40(23.7)$ & 0.92 & (0.56 to 1.50$)$ & 0.728 \\
\hline & $>=3.0$ & 170 & $59(34.7)$ & 1 & & & $43(25.3)$ & 1 & & \\
\hline \multirow[t]{5}{*}{ Testosterone } & Unavail & 345 & $112(32.5)$ & 0.83 & (0.52 to 1.35$)$ & 0.457 & $73(21.2)$ & 0.62 & (0.37 to 1.04$)$ & 0.071 \\
\hline & $<14$ & 74 & $29(39.2)$ & 1.12 & (0.60 to 2.10$)$ & 0,728 & $17(23.0)$ & 0.69 & (0.34 to 1.39$)$ & 0.303 \\
\hline & $14-17$ & 67 & $22(32.8)$ & 0.85 & (0.44 to 1.64$)$ & 0.626 & $23(34.3)$ & 1.21 & (0.62 to 2.37$)$ & 0.572 \\
\hline & $18-23$ & 89 & $23(25.8)$ & 0.60 & (0.32 to 1.14$)$ & 0.121 & $20(22.5)$ & 0.67 & (0.35 to 1.31$)$ & 0.244 \\
\hline & $>=24$ & 93 & $34(36.6)$ & 1 & & & $28(30.1)$ & 1 & & \\
\hline \multicolumn{11}{|l|}{ Medications } \\
\hline & Naive & 118 & $26(22.0)$ & 0.26 & $(0.15$ to 0.45$)$ & $<0.001$ & $17(14.4)$ & 0.32 & $(0.17$ to 0.59$)$ & $<0.001$ \\
\hline ARV & $<=43$ & 137 & $42(30.7)$ & 0.41 & (0.25 to 0.66$)$ & $<0.001$ & $34(24.8)$ & 0.62 & (0.37 to 1.04$)$ & 0.072 \\
\hline & $44-62$ & 138 & $40(29.0)$ & 0.37 & (0.23 to 0.61$)$ & $<0.001$ & $31(22.5)$ & 0.54 & (0.32 to 0.92$)$ & 0.024 \\
\hline & $63-81$ & 137 & $40(29.2)$ & 0.38 & (0.23 to 0.62$)$ & $<0.001$ & $31(22.6)$ & 0.55 & (0.32 to 0.93$)$ & 0.027 \\
\hline (months) & $>81$ & 138 & $72(52.2)$ & 1 & & & $48(34.8)$ & 1 & & \\
\hline${ }^{\wedge}$ Cumulative & Naive & 118 & $26(22.0)$ & 0.34 & $(0.20$ to 0.59$)$ & $<0.001$ & $17(14.4)$ & 0.32 & $(0.17$ to 0.60$)$ & $<0.001$ \\
\hline duration on & $<=82$ & 137 & $39(28.5)$ & 0.48 & (0.29 to 0.79$)$ & 0.004 & $34(24.8)$ & 0.63 & (0.37 to 1.07$)$ & 0.086 \\
\hline NRTI & $83-123$ & 138 & $51(37.0)$ & 0.71 & (0.44 to 1.15$)$ & 0.163 & $39(28.3)$ & 0.75 & (0.45 to 1.26$)$ & 0.280 \\
\hline (months) & $124-160$ & 138 & $42(30.4)$ & 0.53 & (0.32 to 0.87$)$ & 0.012 & $24(17.4)$ & 0.40 & $(0.23$ to 0.71$)$ & 0.002 \\
\hline & $>160$ & 137 & $62(45.3)$ & 1 & & & $47(34.3)$ & 1 & & \\
\hline${ }^{\wedge}$ Cumulative & Naïve & 118 & $26(22.0)$ & 0.42 & $(0.24$ to 0.74$)$ & 0.003 & $17(14.4)$ & 0.43 & $(0.22$ to 0.83$)$ & 0.012 \\
\hline duration on PI & No PI & 93 & $25(26.9)$ & 0.54 & (0.30 to 0.98$)$ & 0.043 & $18(19.4)$ & 0.62 & (0.32 to 1.19$)$ & 0.147 \\
\hline (months) & $<=26$ & 115 & $36(31.3)$ & 0.67 & (0.39 to 1.16$)$ & 0.154 & $30(26.1)$ & 0.90 & (0.50 to 1.62$)$ & 0.736 \\
\hline & $27-41$ & 112 & $37(33.0)$ & 0.73 & (0.42 to 1.26$)$ & 0.255 & $24(21.4)$ & 0.70 & (0.38 to 1.28$)$ & 0.249 \\
\hline & $42-57$ & 116 & $50(43.1)$ & 1.12 & (0.66 to 1.89 ) & 0.672 & $40(34.5)$ & 1.35 & (0.77 to 2.36$)$ & 0.295 \\
\hline & $>57$ & 114 & $46(40.4)$ & 1 & & & $32(28.1)$ & 1 & & \\
\hline Current No PI & Naïve & 118 & $26(22.0)$ & 0.63 & (0.38 to 1.03$)$ & 0.063 & $17(14.4)$ & 0.54 & $(0.30$ to 0.95$)$ & 0.033 \\
\hline & $>=2$ & 64 & $24(37.5)$ & 1.33 & (0.76 to 2.32$)$ & 0.321 & $24(37.5)$ & 1.91 & (1.08 to 3.37$)$ & 0.025 \\
\hline & 1 & 168 & $71(42.3)$ & 1.62 & (1.10 to 2.39 ) & 0.015 & $44(26.2)$ & 1.13 & (0.74 to 1.74$)$ & 0.578 \\
\hline & 0 & 318 & $99(31.1)$ & 1 & & & $76(23.9)$ & 1 & & \\
\hline Current No & naive & 118 & $26(22.0)$ & 0.63 & (0.38 to 1.05$)$ & 0.075 & $17(14.4)$ & 0.50 & $(0.28$ to 0.88$)$ & 0.017 \\
\hline NNRTI & 0 & 258 & $104(39.6)$ & 1.52 & (1.07 to 2.15$)$ & 0.020 & $70(27.1)$ & 1.10 & (0.75 to 1.60$)$ & 0.634 \\
\hline & 1 & 292 & $90(30.8)$ & 1 & & & $74(25.3)$ & 1 & & \\
\hline Experienced to & Naïve & 118 & $26(22.0)$ & 0.71 & (0.38 to 1.34$)$ & 0.295 & $17(14.4)$ & 0.70 & (0.34 to 1.47$)$ & 0.349 \\
\hline number of & $>=4$ & 198 & $87(43.9)$ & 1.98 & (1.15 to 3.39 ) & 0.014 & $66(33.3)$ & 2.09 & (1.14 to 3.83$)$ & 0.017 \\
\hline different NRTIs & 3 & 99 & $42(42.4)$ & 1.86 & (1.01 to 3.42 ) & 0.047 & $30(30.3)$ & 1.82 & (0.92 to 3.59$)$ & 0.086 \\
\hline pre current & 2 & 162 & $39(24.1)$ & 0.80 & (0.44 to 1.44$)$ & 0.454 & $31(19.1)$ & 0.99 & (0.51 to 1.91$)$ & 0.972 \\
\hline therapy & 1 & 3 & $1(33.3)$ & 1.26 & (0.11 to 4.52$)$ & 0.853 & $0(0.0)$ & unstable & - & - \\
\hline & $\begin{array}{r}\text { currently on } 1^{\text {st }} \\
\text { line }\end{array}$ & 88 & $25(28.4)$ & 1 & & & $17(19.3)$ & 1 & & \\
\hline Experienced to & Naïve & 118 & $2(22.0$ & 0.72 & (0.41 to 1.28$)$ & 0.269 & $17(14.4)$ & 0.67 & (0.34 to 1.29$)$ & 0.230 \\
\hline number of & $>=3$ & 135 & $68(50.4)$ & 2.60 & (1.58 to 4.29$)$ & 0.000 & $49(36.3)$ & 2.26 & (1.31 to 3.89 ) & 0.003 \\
\hline different PI's pre & $1-2$ & 276 & $8731.5)$ & 1.18 & (0.75 to 1.85$)$ & 0.469 & $67(24.3)$ & 1.27 & (0.77 to 2.09$)$ & 0.345 \\
\hline current therapy & $\begin{array}{r}\text { currently on } 1^{\text {st }} \\
\text { line }\end{array}$ & 139 & $40(28.1$ & 1.00 & & & $28(20.1)$ & 1 & & \\
\hline
\end{tabular}




\begin{tabular}{|c|c|c|c|c|c|c|c|c|c|c|}
\hline Variable & & $\begin{array}{l}\text { Total } \\
(668)\end{array}$ & $\begin{array}{c}\text { EDF } \\
\text { n(\%) } \\
(n=220)\end{array}$ & $\begin{array}{l}\text { Odds } \\
\text { Ratio }\end{array}$ & $\begin{array}{c}95 \% \\
\text { confidence } \\
\text { interval }\end{array}$ & $\begin{array}{c}\text { Wald } \\
\text { statistics } \\
\text { p-value }\end{array}$ & $\begin{array}{c}\text { LSD } \\
n(\%) \\
(n=161)\end{array}$ & Odds Ratio & $\begin{array}{c}95 \% \text { confidence } \\
\text { interval }\end{array}$ & $\begin{array}{c}\text { Wald } \\
\text { statistics } \\
p \text {-value }\end{array}$ \\
\hline \multicolumn{11}{|c|}{ Other medications } \\
\hline \multirow[t]{2}{*}{ Antidepressants } & Yes & 51 & $24(47.1)$ & 1.91 & (1.07 to 3.39 ) & 0.028 & $21(41.2)$ & 2.38 & (1.32 to 4.30$)$ & 0.004 \\
\hline & no & 617 & $196(31.8)$ & 1 & & & $140(22.7)$ & 1 & & \\
\hline \multirow[t]{2}{*}{ Psychotropics } & Yes & 37 & $24(64.9)$ & 4.10 & (2.04 to 8.22$)$ & $<0.001$ & $20(54.1)$ & 4.09 & $(2.09$ to 8.01$)$ & $<0.001$ \\
\hline & no & 631 & 196(31.1) & 1 & & & $141(22.4)$ & 1 & & \\
\hline \multirow[t]{2}{*}{ Sildenafil } & Yes & 108 & $48(44.4)$ & 1.80 & (1.19 to 2.75$)$ & 0.006 & $36(33.3)$ & 1.74 & (1.11 to 2.72 ) & 0.015 \\
\hline & No & 560 & $172(30.7)$ & 1 & & & $125(22.3)$ & 1 & & \\
\hline \multirow{2}{*}{$\begin{array}{l}\text { Testosterone } \\
\text { therapy }\end{array}$} & Yes & 32 & $18(56.3)$ & 2.76 & $(1.35$ to 5.66$)$ & 0.006 & $11(34.4)$ & 1.70 & (0.80 to 3.60$)$ & 0.168 \\
\hline & No & 636 & $202(31.8)$ & 1 & & & $150(23.6)$ & 1 & & \\
\hline \multirow[t]{2}{*}{ Alprostadil } & Yes & 23 & $14(60.9)$ & 3.31 & (1.41 to 7.78$)$ & 0.006 & $8(34.8)$ & 1.72 & (0.71 to 4.12$)$ & 0.228 \\
\hline & No & 645 & $206(31.9)$ & 1 & & & $153(23.7)$ & 1 & & \\
\hline \multirow{2}{*}{$\begin{array}{l}\text { Anti- } \\
\text { hypertensives }\end{array}$} & Yes & 25 & $15(60.0)$ & 3.20 & (1.42 to 7.26$)$ & 0.005 & $7(28.0)$ & 1.23 & $(0.51$ to 3.01$)$ & 0.643 \\
\hline & no & 643 & $205(31.9)$ & 1 & & & $154(24.0)$ & 1 & & \\
\hline \multirow[t]{2}{*}{ Fibrates/statins } & Yes & 37 & $19(51.4)$ & 2.26 & $(1.16$ to 4.40$)$ & 0.017 & $12(32.4)$ & 1.55 & $(0.76$ to 3.17$)$ & 0.226 \\
\hline & no & 631 & $201(32.1)$ & 1 & & & $149(23.6)$ & 1 & & \\
\hline
\end{tabular}

$\wedge$ If no of NRTI or no of PI (unboosted) > 1 then cumulative duration on drug is multiplied by no of same class ARV drugs

Data for insomnia, pain in joints, LDL cholesterol, ischaemic heart disease, methadone not shown. 


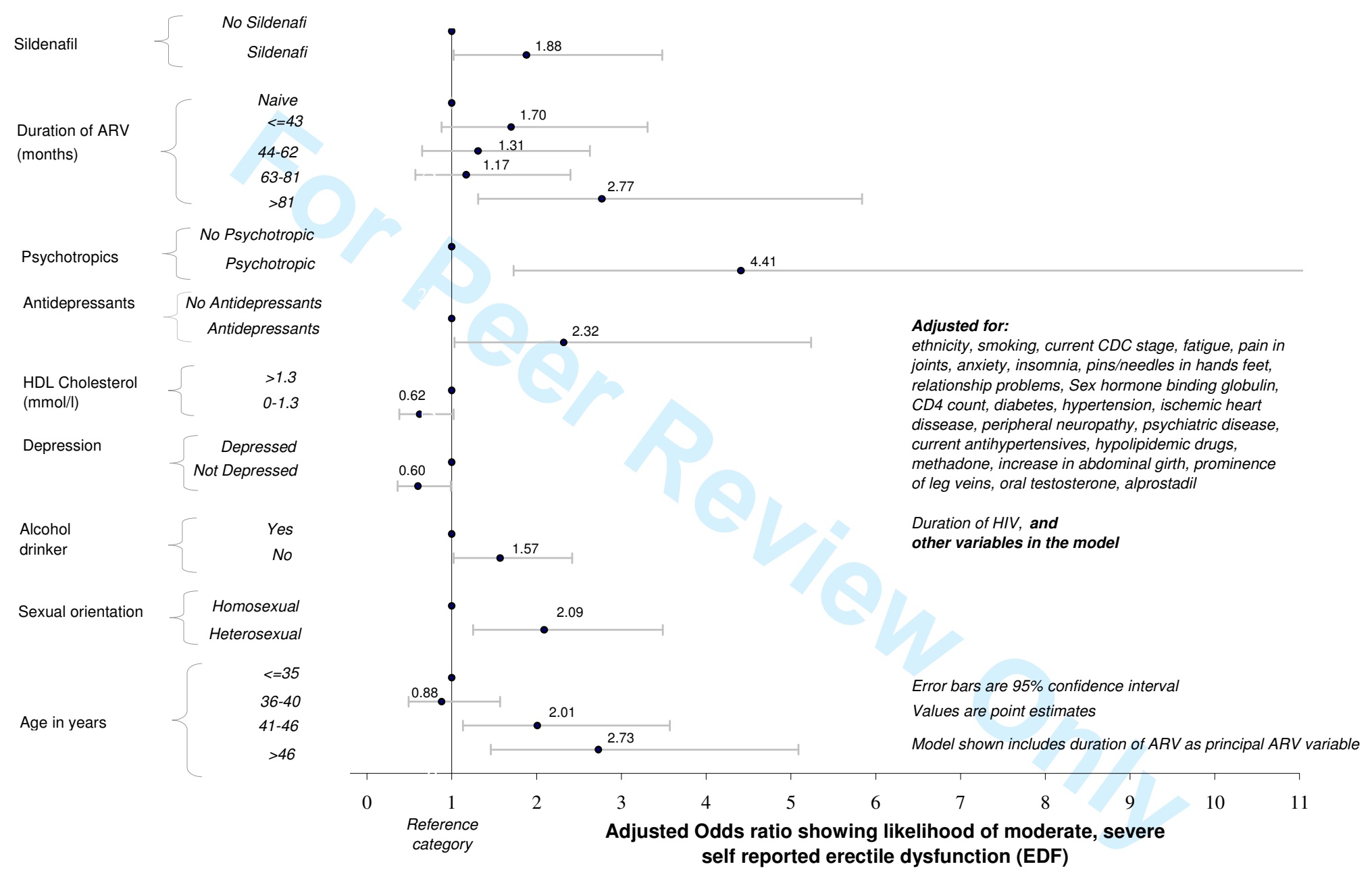

Figure 1: Multivariable logistic regression model showing likelihood of moderate/severe erectile dysfunction with model containing duration antiretroviral treatment (ARV) as principal ARV category. 


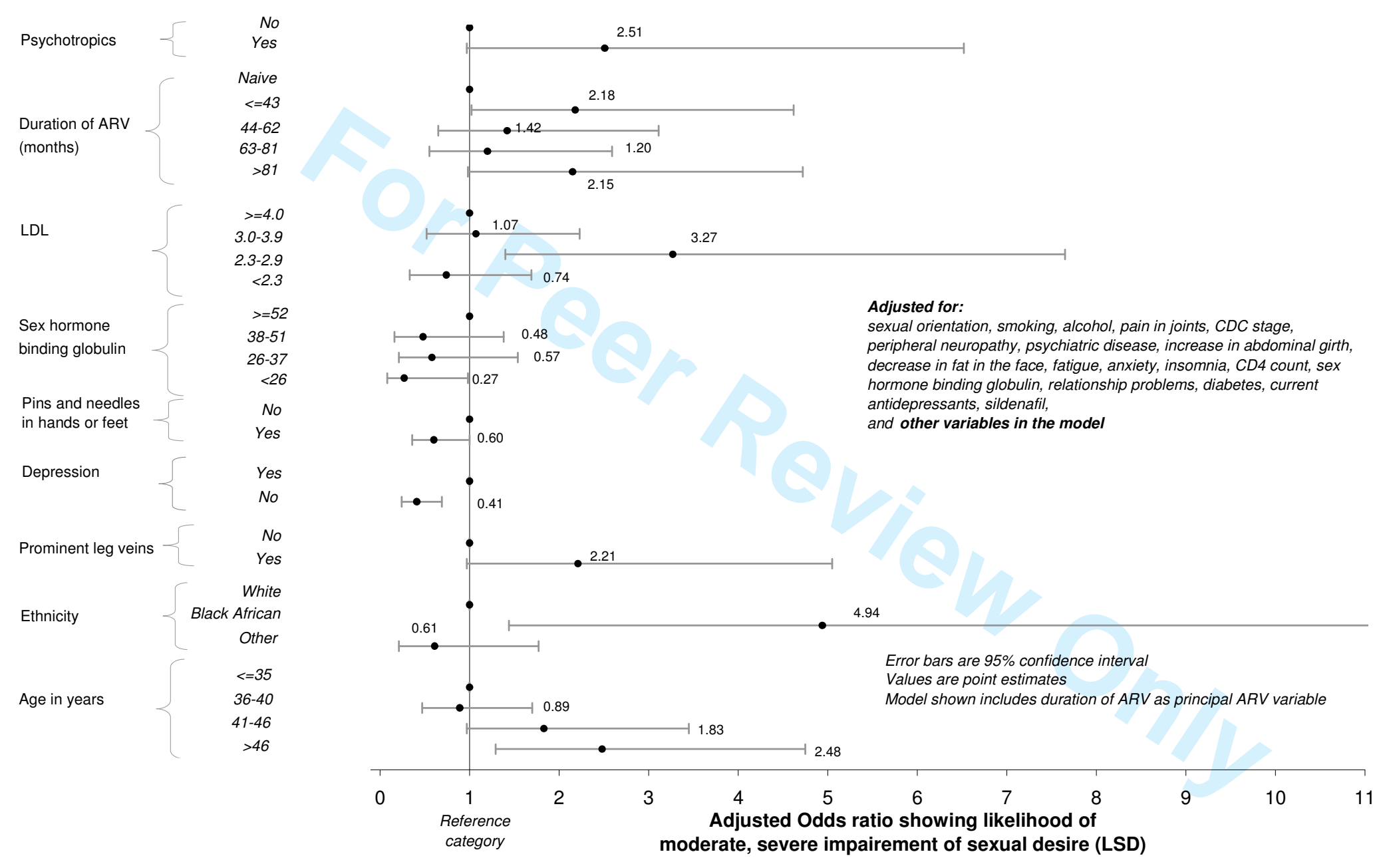

Figure 2: Multivariable logistic regression model showing likelihood of moderate/severe impairment of sexual desire with model containing duration antiretroviral treatment (ARV) as principal ARV category. 
| Sdpaper07,

Sexual dysfunction in HIV positive men is multi-factorial: a study of prevalence and associated factors.

David Asboe $^{\mathrm{a}}$, Jose Catalan ${ }^{\mathrm{b}}$, Sundhiya Mandalia ${ }^{\mathrm{a}}$, Nikos Dedes ${ }^{\mathrm{c}}$, Eric Florence ${ }^{\mathrm{d}}$, Ward

Schrooten ${ }^{d}$, Christiana Noestlinger ${ }^{d}$ and Robert Colebunders ${ }^{d}$ on behalf of the EuroSupport Study Group.

aDirectorate of HIV/GU Medicine, Chelsea and Westminster Hospital, London, UK;

${ }^{b}$ Psychological Medicine, South Kensington and Chelsea Mental Health Centre, London, UK;

'Synthesis, Athens, Greece; Institute of Tropical Medicine, Department of Clinical Sciences, Antwerp, Belgium.

Key words: sexual dysfunction; impotence; antiretroviral therapy, highly active.

Word count: 2307

Correspondence to: David Asboe, Chelsea and Westminster Hospital, 369 Fulham Road, London, UK, SW10 9NH,

david.asboe@ chelwest.nhs.uk.

Telephone +442088466131, Fax +442088466198 


\section{ABSTRACT}

To establish the prevalence of sexual dysfunction amongst HIV positive men and to determine the factors associated with dysfunctionwe conducted a cross-sectional study jn seven European HIV treatment centres. Data on medical history, antiretroviral treatment and laboratory results were collected by interview and case record review. Sexual function was evaluated by the participant self-completion of a questionnaire based on the International Index of Erectile Function (IIEF).711/929 (77\%) study participants returned the questionnaire. Data from 668 respondents were included (72\%). Thirty-three percent $(95 \% \mathrm{Cl} 29.4 \%$ to $36.5 \%$ ) had moderate/severe erectile dysfunction (EDF) and 24 percent (95\% $\mathrm{Cl} 20.9 \%$ to 27.3\%) had moderate to severe impairment of sexual desire. Variables significantly associated with EDF in multivariable analysis were older age (greater than 40 years), heterosexual status, non-alcohol drinking status, depression, antidepressants, psychotropic medications and duration of ARV therapy. Low sexual desire (LSD) was associated with older age (greater than 40 years), depression and Black African ethnicity.

We establish that EDF and LSD are common in both ARV naïve and ARV experienced, HIV positive individuals. EDF was associated with long duration of ARV treatment with a significantly increased risk of dysfunction in the quartile with the longest period of exposure. No significant association was seen with specific classes of anti-retrovirals. Older age, and depression were the variables most consistently associated with both EDF and LSD.
Deleted: Objectives:

Deleted:

Deleted: I Methods: C

Deleted: conducted

Deleted: Results: 
Sdpaper07

Since the introduction of highly active antiretroviral therapy (HAART) there have been numerous reports of increased erectile dysfunction (EDF) in men. In these studies prevalence rates of dysfunction of up to $70 \%$ have been described and in some the dysfunction has been linked with antiretroviral treatment (ARV), particularly protease inhibitors (PIs) (1-6)

However proving a link between, this unwanted outcome and ARV treatment, is problematic. First, HIV infection may be associated with sexual dysfunction. There are several reports of sexual dysfunction that predate the introduction of $\operatorname{HAART}_{1}(7,8)$ and conditions commonly seen within the HIV context such as depression, peripheral neuropathy and hypogonadism are associated with sexual dysfunction in other settings. Secondly establishing associations with particular drugs or classes of drugs is difficult, as these agents are used in combinations. Furthermore some of the ARV-associated toxicities, for example mitochondrial toxicities such as peripheral neuropathy can cause effects which persist. This could lead to the adverse effect being attributed wrongly to the treatments being taken at the $\underline{\text { time of assessment rather than to the treatment responsible. }}$

$\underline{\text { In assessing the prevalence of sexual dysfunction in different groups, comparison of rates }}$ acoss different studies may also be misleading. Even when using the same assessment tool (International Index of Erectile Function (IIEF)(9)) rates in different studies can vary markedly. For example the prevalence of moderate or severe erectile dysfunction reported in a general Austrian population (10) was as low as $5.8 \%$ while it was as high as $28 \%$ in a Singaporean study (11). It is likely that such differences are caused by factors such as age, co-morbidities and prescribed medications. In the studies in HIV positive men, factors such as these have in general been poorly controlled for, hence we believe the confidence with which conclusions can be drawn from these studies is weakened.

Deleted: I

We do not think that studies which link sexual dysfunction with protease inhibitors have adequately taken into account multiple other possible confounders. ๆ
Deleted: There have been numerous reports of sexual dysfunction in HIV positive men with prevalence rates of up to $70 \%$ being described (1-6). Some of these studies show an association between sexual dysfunction and protease inhibitor (PI) containing anti-retroviral combinations while some papers are unable to demonstrate this link.
Deleted: Attributing a link b

Deleted: etween an

Deleted:

Deleted: drug

Deleted: in the HIV field

Deleted: in this case, the disease itself

Deleted: highly active anti-retrovira therapy (HAART)

Deleted: certainly

Deleted: not only

Deleted: but in sequences of combinations. 
The primary objectives of this study therefore are to establish the prevalence of erectile

dysfunction (EDF) and low sexual desire (LSD) in both ARV naïve and experienced HIV positive men attending HIV outpatient centres across Europe and to define the variables associated with sexual dysfunction. Due to the large number of variables that are potentially contributors to dysfunction a large amount of data relating to these variables was collected. This not only included data relating to current HIV treatments but also previous treatments. Significant factors identified in univariate analysis were then examined further in a multivariable analysis.

Deleted: By taking account of factors previously demonstrated to be important our aim is to explore whether there is an independent association between sexual dysfunction and anti-retroviral dysfunction ๆ

\section{METHODS}

Between April 2000 and May 2002 HIV positive men attending one of seven European HIV treatment centres for routine HIV care were invited to join the study (the centres are those that were participants within the Eurosupport network and each centre obtained local ethics committee approval). If consent was given two study components were administered. The study team completed the first part. This was a standardised data collection proforma that examined aspects of the medical history, antiretroviral treatment and laboratory results (total and fractionated cholesterol, triglycerides, testosterone, prolactin, lutenising hormone (LH), follicle stimulating hormone (FSH) and serum glucose). A large number of clinical data variables were examined in order to explore many possible associations.

The second part was a questionnaire (available in one of seven languages, English, French, German, Spanish, Italian, Dutch or Swedish) and was given to the participant to complete at home. This included questions assessing sexual function and other symptoms. Individuals 
Sdpaper07.

were then asked to return this anonymous response by post to the coordinating centre. A code was used to link this to the data collected by the physician.

Sexual function was assessed within the questionnaire by questions based on the International Index of Erectile Function (9). We adapted the questionnaire given to homosexual men (MSM) by including questions assessing erectile and other sexual functions related to oro-genital and both insertive and receptive ano-genital sex. This questionnaire was piloted amongst MSM prior to the study.

Categories of sexual function assessed were erectile function, sexual desire, orgasmic function, intercourse satisfaction and overall satisfaction. Based on these scores each aspect of sexual function was categorised as normal or as mild, moderate or severe dysfunction. The analysis presented relates to the outcomes moderate to severe erectile dysfunction (EDF) and moderate to severe impairment of sexual desire (LSD). Univariate logistic regression analysis was used to identify risk factors associated with these outcomes. Variables found to be significant $(P<0.15)$ were used to build multivariable models in order to identify significant risk factors. Those variables co-correlated with other variables were left in the model to adjust for residual confounding. Due to the interaction between different ARV variables different multivariable models were run examining the effect on the model of each of those ARV factors found to be significant in univariate analysis. The model presented includes ARV duration as this was the strongest association seen. The multivariable model presents significant independent predictors after adjusting for other variables in the model. All $p$ values presented are 2-tailed. To preserve degrees of freedom we examined CD4 counts categorised into groups using median and interquartile ranges with a separate category for missing data.

To examine links between sexual dysfunction and ARV combinations, individuals were categorised as either ARV naïve, ARV experienced but PI naïve, PI experienced and 
currently taking $\mathrm{PI}$ or $\mathrm{PI}$ experienced but not currently taking a drug from this class.

Categories relating to the number of PIs, NRTIs, and non-nucleoside reverse transcriptase inhibitors (NNRTIs) both currently and previously received were also examined. In order to negate the confounding of previous treatments on current treatment a sub-analysis of those on their first line ARV only was also performed.

As there was no consensus case definition for lipodystrophy at the time of study design, this was simply defined as having at one or more of the following symptoms confirmed by clinical examination: increase in abdominal girth, decrease of fat in the face, or prominence of leg veins. Medications for psychiatric disorders assessed included antidepressants and other psychotropics (sedatives and major tranquillisers).

\section{RESULTS}

Of the 929 individuals who consented for the study $711(77 \%)$ returned the questionnaire. Non-responders were more likely than responders to have an AIDS diagnosis $(26.6 \%$ versus $20.5 \%, p=0.005)$ and to ever have had diagnosed psychiatric disease $(5.0 \% \vee 1.8 \%$, $p=0.033)$. Responders were more likely to be using methadone $(5.9 \% \vee 1.4 \%, p=0.005)$. There were no significant differences between responders and non-responders in reported co-morbidities or usage of sildenafil, testosterone, antidepressants, or other psychotropic medication. Forty-four responses were excluded due to invalid or incomplete data. The overall response rate was $71.9 \%$. In all 486 of the participants were homosexual men (MSM) and 182 heterosexual men (MSW), 552 were ARV experienced and 116 ARV naïve. Two 
| Sdpaper07,

hundred and twenty $(32.9 \%, 95 \% \mathrm{Cl} 29.4 \%$ to $36.5 \%)$ were categorised as having

moderate/severe EDF and $161(24.1 \%, 95 \%$ Cl 20.9 to $27.3 \%)$ moderate/severe LSD.

\section{Erectile dysfunction}

Overall $35 \%$ of ARV experienced participants reported moderate or severe EDF compared with $22 \%$ of those who were ARV naïve. The factors associated with EDF in univariate analysis are shown in Table 1. When a multivariable model was run with treatment experienced versus naïve as the ARV associated variable this association was not found to be significant (OR ARV naïve 0.69;0.39-1.22, $\mathrm{p}=0.201$ ). However examining duration of ARV use we found that the most experienced group (greater than 81 months on treatment) were significantly more likely than the other groups of ARV experienced and naïve participants to report EDF (figure 1). We also performed models to examine whether there was an association between EDF and duration of exposure to either NRTIs or to PIs. In neither of these multivariable analyses was a significant association seen. 


\section{Low sexual desire}

Overall $26 \%$ of treatment experienced participants reported moderate to severe reduction in sexual desire compared with $13 \%$ of those who were ARV naïve. While this difference was significant in univariate analysis this was not the case when we used this as the ARV variable in multivariable analysis (OR ARV naïve $0.63,0.32$ 1.21, $\mathrm{p}=0.166$ ). We did not demonstrate an association between LSD and any ARV related variable.

When we analysed those individuals on their first line therapy only $(n=86)$ the variables significantly associated with EDF were older age, heterosexual status, smoking status, reported fatigue, pain in bones and joints and pins and needles in hands and feet. Being on a protease inhibitor containing combination was not associated with EDF.

As a supplement to the study we asked participants reporting EDF whether they had used therapies to treat this condition. The most frequent reported therapy was sildenafil used by 112 individuals (16\%). Smaller numbers reported using testosterone, growth hormone, yohimbine, alprostadil and papaverine. Twenty-six individuals reported they had changed their ARV combination and 26 reported they had stopped their ARV drugs in an attempt to improve sexual function. Within these two groups twenty-two individuals (42\%) reported either manoeuvre to have been successful. 


\section{DISCUSSION}

While in univariate analysis ARV-experienced participants were significantly more

likely than ARV-naïve individuals to experience EDF, when the data were adjusted in

multivariable analysis we were unable to demonstrate a significantly higher

prevalence of dysfunction in this group. In running several models the only treatment

related variable associated with a significantly increased prevalence of dysfunction

was in the quartile of patients with the longest duration of ARV treatment (greater

than 81 months) where the relative risk of moderate/severe EDF was approximately

$\underline{\text { three times that seen in ARV naïve individuals. Increased rates of dysfunction were }}$

not seen in individuals with less exposure to ARVs compared to treatment naïve

individuals.

Most studies of EDF in people with HIV infection done since the introduction of

HAART have looked only at individuals taking ARV treatment and so direct

comparison with ARV naïve groups has not been possible. In the one study that did

look at both groups, sexual dysfunction was seen in many more of the ARV treated

individuals. However in this study the method of assessment was not well described

nor were factors such as age controlled for (5).

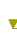

We found no assciation between EDF and either categorical exposure or duration of

exposure to specific classes of NRTI or PI therapy. While several studies have

demonstrated an association with PIs $(1,2,3,5)$, it is interesting that neither of the two

groups that utilised the IIEF found a link with a particular class of medications $(4,6)$.

That EDF was associated with duration of $A R V$ exposure allied with the fact that both

NRTIs and Pls are associated with toxicities that might be related to cumulative

exposure (for example metabolic and mitochondrial toxicities) raises the possibility
Deleted: By patient self-assessment one third of the study population were categorised as having moderate to

severe EDF. Making a definitive

statement about the relative risk of

EDF in an HIV positive compared to an HIV negative population is difficult as this comparison has not been

done within a single study and the comparison of rates from different studies is problematic. If however we take studies which have utilised the IIEF instrument in an unselected (and presumed HIV negative) group we find overall reported rates of

moderate/severe EDF range from $5.8 \%$ in an Austrian study (10) to $11.8 \%$ in a Korean study (11) to $28 \%$

in a Singaporean study (12). In a

large study using a different

questionnaire the Massachussets

Male Aging Study (MMAS)

categorised $35 \%$ of men over the age

of 40 years old as having moderate to complete impotence (13). The

prevalence of moderate/severe EDF in a similar age group in our study was $44 \%$. 1

Deleted: We were unable to demonstrate an association between EDF and any aspect of ARV treatment except in the group treated for the longest duration (greater than 81 months). Most studies of EDF in people with HIV infection done since the introduction of HAART have looked only at individuals taking ARV treatment and none have collected comprehensive data on other variables likely to have an influence. While several studies demonstrate an association with protease inhibitors

Deleted: $(1,2,3,5)$

Deleted: In this study compared to patients who were naive to ARV, patients who were ARV experienced were significantly more likely to experience EDF. However, when the data were adjusted for factors which were either confounding or had residual effects this association was found to be non significant. No association was demonstrated when we examined models testing either categorical exposure or duration of exposure to specific classes of (NRTI or $\mathrm{PI})$ therapy.

\section{Deleted: ๆ}

The prevalence of moderate/severe LSD was lower than that of EDF. No ARV associated variable that we tested was associated with LSD in multivariable analysis.

The finding $t$ 
that sexual dysfunction may in some way be related to these toxicities. For example erectile dysfunction has been seen in association with peripheral neuropathy and is also hypothesised to be associated with endothelial dysfunction seen in forms of metabolic syndrome $(13,14)$. We were not however able to demonstrate a link with clinical manifestations of such toxicities except for the single association of reported tingling in the extremities (indicative of peripheral neuropathy) and LSD. Lallemand has also reported the absence of an association between EDF and lipodystrophy (4).

Older age was the variable most strongly associated with both EDF and LSD aspects of decreased sexual function. The risk of moderate to severe EDF for an individual in the oldest quartile was almost three times that for someone in the youngest quartile. Studies of EDF in the general population consistently demonstrate older age as one of the variables most strongly associated with dysfunction.

There was an association between anti-depressants and other psychotropic medication and EDF. Although anti-depressants, psychotropic medications, antihypertensives and statins $(15,16)$ have all been previously linked to sexual dysfunction it remains problematic proving causality particularly when underlying conditions such as depression (1ㄱ) may be exerting an influence. In the Massachusettts male aging study the apparent associations between medications and sexual dysfunction mostly disappeared when adjustment for co-morbidities and health behaviours was made (18). While we enquired broadly about relationship problems we did not explore some other issues that might have had influence. $\underline{\text { Previously factors such as discordant HIV status, disclosure status and the type and }}$ nature of sexual relationships have been postulated to affect sexual function.

Most participants who switched or stopped ARV medications due to EDF came off PI based regimens. While a percentage of these individuals reported improvement it is

Deleted: 6

Deleted: 7

Deleted: 8
Deleted: Furthermore it is possible sexual dysfunction may contribute to depression. It was therefore not possible to demonstrate an

independent association with these parameters. In the Massachusettts male aging study the apparent associations between medications and sexual dysfunction mostly disappeared when adjustment for comorbidities and health behaviours was made (19). While we enquired broadly about relationship problems we did not explore some other issues that might have had influence.

Previously factors such as discordant HIV status, disclosure status and the type and nature of sexual

relationships have been postulated to affect sexual function 
| Sdpaper07,

not necessarily correct to conclude from this that the ARV agents were responsible for the dysfunction.

\section{The prevalence of moderate/severe LSD was lower than that of EDF. No ARV}

associated variable that we tested was associated with LSD in multivariable analysis.

There are limitations to the study. The participation of centres and subjects from different countries presented many challenges. While guided by study protocols and proformas there may have been differences in the way in which individuals were recruited and how data was collected. Although the study recruitment protocol was inclusive and non-selective it is possible that there was a bias in patient selection and that therefore the study group is not representative of the entire clinic population. While the MSM adapted questionnaire was piloted it was not formally validated. It is possible that some of the increased risk of sexual dysfunction seen in heterosexual men relates to assessment of dysfunction rather than any inherent difference. Lastly the large number of variables examined increases the possibility of finding a spurious $\underline{\text { association by chance and also the possibility that a positive association was lost by }}$ the dilutional effect of including so many variables.

We have demonstrated a high prevalence of sexual dysfunction in both ARV treatment naïve and experienced individuals. Sexual dysfunction is associated with older age, depression and longer duration of anti-retroviral treatment. We were not able to demonstrate an association between EDF and a particular class of ARV or with specific HIV or drug-related toxicities. That sexual dysfunction is multi-factorial is an important finding. For those affected it is often a major concern and leads to considerable diminution in quality of life. There is also evidence that the attribution of sexual dysfunction to protease inhibitors is contributing to lower levels of adherence over time (19). In these circumstances it remains important to discuss with patients

Deleted: While the study recruitm
protocol was inclusive and nonselective it is possible that there was a bias in patient selection and that therefore the study group is not representative of the entire clinic population.
Deleted: There may also have been variations in the way participants rexpond to question function.
sexual
Deleted:

ๆ 
the uncertainty over this association and to assess, investigate and treat this condition appropriately. Meanwhile further, preferably prospective, study is required so that any relationship with $A R V$ or related conditions can be further defined.

\section{Acknowledgements}

The participating centres (and investigators) were St Stephen's Aids Trust, Chelsea \& Westminster Healthcare, London, United Kingdom (Asboe D). Instito Scientifico Ospedale S. Raffaele, Milan, Italy (Finazzi R). Infektionsambulanz, Ludwig Maximilians Universität, München, Germany (Goebel FD). Universidad Complutense, Madrid, Spain (Gordillo V). General Hospital of Athens, Greece (Kosmidis J). Söder Hospital, Stockholm, Sweden (Nilsson Schönnesson, L Venhälsan). Otto Wagner Spital, Wien, Austria (Vetter N, Koitz G). North Manchester General Hospital, Manchester, United Kingdom (Wilkins EG).

Competing interests: None.

Financially supported by: The European Commission's DG V, (grant agreement SI2.299480, 2000CVG4-025),

\section{REFERENCES}

1. Martinez E, Collazos J, Mayo J et al: Sexual dysfunction with protease inhibitors. Lancet 1999;353:810. 
2. Schrooten W, Colebunders R, Youle M et al: Sexual dysfunction associated with protease inhibitors containing highly active antiretroviral treatment. AIDS 2001;15:1019-1023.

3. Colson E, Keller M, Saz P, et al: Male sexual dysfunction associated with antiretroviral therapy. JAIDS 2002:30:27-32.

4. Lallemand F, Salhi Y, Linard F, et al: Sexual dysfunction in 156 ambulatory HIV infected men receiving high active antiretroviral therapy combinations with and without protease inhibitors. JAIDS 2002;30:187-190.

5. Collazos J, Mayo J, Martinez E, et al: Sexual dysfunction in HIV infected patients treated with highly active antiretroviral therapy. JAIDS 2002;31:322-326.

6. Sollima S, Maurizio O, Muscia F et al: Protease inhibitors and erectile dysfunction Letters. AIDS 2001:15:2331-2333.

7. Catalan J, Klimes I, Bond A, Day A, Garrod A, Rizza C. The psychosocial impact of HIV infection in men with haemophilia: controlled investigation and factors associated with psychiatric morbidity. Journal Psychosomatic Research, 1992;36(5):409-416 .

8. Catalan J, Klimes I, Day A, Garrod A, Bond A, Gallwey J. The psychosocial impact of HIV infection in gay men: A controlled investigation and factors associated with psychiatric morbidity. British Journal Psychiatry, 1992;161:774-778. 
9. Rosen RC, Riley A, Wagner G, Osterloh IH, Kirkpatrick J, Mishra A. The international index of erectile function (IIEF): a multidimensional scale for assessment of erectile dysfunction. Urology. 1997 49:822-30.

10. Madersbacher s, Temml C, Racz U et al. Prevalence and risk factors for erectile dysfunction in Austria-analysis of a health screening project. Wien Klin Wochenschr. 2003;115:822-30.

11. Tan JK, Hong CY, Png DJ, Liew LC, Wong ML. Erectile dysfunction in Deleted: 11. Cho BL, Kim YS, Choi YS et al. Prevalence and risk factors for erectile dysfunction in primary

care: results of a Korean study. International Journal Impotence Research. 2003;15:323-8. ๆ

Singapore:prevalence and its associated factors- a population based study.

Deleted: 2

Singapore Medical Journal, 2003;44:20-6.

12. Feldman H, Goldstein I, Hatzichristou D, Krane R, McKinlay J. Impotence and its Deleted: 3 medical and pshychosocial correlates: results of the Massachusetts male aging study. Journal Urology. 1993;151:54-61.

13. Esposito K, Giugliano D. Obesity, the metabolic syndrome, and sexual dysfunction. International Journal Impotence Research. 2005 17(5):391-8.

14. Fonseca V, Jawa A. Endothelial and erectile dysfunction, diabetes mellitus, and Deleted: 5 the metabolic syndrome: common pathways and treatments. American Journal Cardiology. 2005;96:13M-18M.

15. Bruckert E, Giral P, Heshmati HM, Turpin G. Men treated with hypolipidaemic Deleted: 6 drugs complain more frequently of erectile dysfunction.Journal Clinical Pharmacological Therapy. 1996 Apr;21(2):89-94. 
| 16. Rizvi K, Hampson JP, Harvey JN. Do lipid-lowering drugs cause erectile dysfunction? A systematic review. Family Practice. 2002 Feb;19(1):95-8. 17. Araujo AB, Durante R, Feldman HA, Goldstein I, McKinlay JB. The relationship
between depressive symptoms and male erectile dysfunction: cross-sectional results from the Massachusetts Male Aging Study. Psychological Medicine. 1998 JulAug;60(4):458-65.

18. Derby CA, Barbour MM, Hume AL, McKinlay JB. Drug therapy and prevalence of erectile dysfunction in the Massachusetts Male Aging Study cohort.

Pharmacotherapy. 2001, 21(6):676-83.

19. Trotta MP, Ammassari A, Cozzi-Lepri A, et al. Adherence to highly active antiretroviral therapy is better in patients receiving non-nucleoside reverse transcriptase inhibitor-containing regimens than in those receiving protease inhibitorcontaining regimens. AIDS. 2003;17(7):1099-102.
Deleted: 8

Deleted: 9

Deleted: 20 